\title{
DIREITO À MEMÓRIA E À VERDADE E A ALTERAÇÃO DE NOMES DE LOGRADOUROS PÚBLICOS QUE HOMENAGEIAM REPRESENTANTES DA DITADURA MILITAR
}

RIGHT TO MEMORY AND THE TRUTH AND CHANGE OF NAMES OF PUBLIC PROCEEDINGS THAT HOMENAGE REPRESENTATIVES OF THE MILITARY DICTATORSHIP

Fábio Cantizani Gomes ${ }^{1}$

ISSUE DOI: $10.21207 / 1983.4225 .517$

\section{RESUMO}

Um dos principais objetivos de qualquer justiça de transição é a busca pela verdade e o esclarecimento dos atos atentatórios aos direitos humanos cometidos durante um período de exceção. Esta busca, além de possibilitar a responsabilização dos agentes, possui o caráter pedagógico de educar as gerações posteriores numa cultura democrática e de respeito aos direitos humanos. As políticas de memória utilizam, dentre outros elementos, do estabelecimento de espaços que simbolizam e evocam a luta de resistência contra os regimes autoritários. Uma das práticas mais frequentes destes espaços de memória é a alteração de nomes de logradouros públicos que homenageiam figuras ligadas aos regimes ditatoriais. Embora não haja consenso sobre a utilização deste recurso, há recomendação expressa para sua utilização em nosso país, como medida simbólica de rompimento com o

\footnotetext{
${ }^{1}$ Mestre em direito pela UNESP-Franca. Professor de Direito Constitucional da Faculdade de Direito de Franca e da Universidade de Franca.
} 
passado autoritário e estabelecimento de uma nova sociedade fundamentada nos valores democráticos e de respeito aos direitos humanos.

Palavras-chave: Justiça de transição. Direito à memória. Ditadura militar. Logradouros públicos.

\section{ABSTRACT}

One of the main objectives of any transitional justice is the search for truth and clarification of acts that violate human rights during a period of exception. This search, in addition to making the agents responsible, has the pedagogical character of educating later generations in a democratic culture and respect for human rights. Memory policies use, among other elements, the establishment of spaces that symbolize and evoke the struggle of resistance against authoritarian regimes. One of the most frequent practices of these spaces of memory is the change of names of public places that honor figures related to dictatorial regimes. Although there is no consensus on the use of this resource, there is an express recommendation for its use in our country, as a symbolic measure of rupture with the authoritarian past and establishment of a new society based on democratic values and respect for human rights.

Keywords: Transitional justice. Right to memory. Military dictatorship. Public landmarks

1

\section{JUSTIÇA DE TRANSIÇÃO E O DIREITO À MEMÓRIA E À VERDADE}

\subsection{JUSTIÇA DE TRANSIÇÃO E A BUSCA DA VERDADE}

Desde o final da segunda guerra mundial, com o conhecimento das barbáries praticadas pelo regime nazifascista, surgem as primeiras ideias de criação de mecanismos de responsabilização e punição de agentes perpetradores destas atrocidades, juntamente com a previsão de alguma forma de compensação para as vítimas ou seus familiares. 
A partir da década de 80 , surgem as ideias de se estabelecer uma justiça de transição para implementar estes objetivos em sociedades pósconflito, em que tenham ocorrido graves violações aos direitos humanos.

O professor da Universidade de Direito de Nova Iorque e vicepresidente do Centro Internacional de Justiça de Transição, Paul Van Zyl, conceitua justiça de transição como os esforços implementados "para a construção da paz sustentável após um período de conflito, violência em massa ou violação sistemática dos direitos humanos". ${ }^{2}$

Este mesmo autor, citando um consenso estabelecido pela Corte Interamericana de Direitos Humanos, aponta que são objetivos reconhecidos do Estado, após um período de graves violações aos direitos humanos, "processar os perpetradores, revelar a verdade sobre crimes passados, conceder reparações às vítimas, reformar as instituições perpetradoras de abuso e promover a reconciliação". ${ }^{3}$

Logicamente que as mais graves violações aos direitos humanos como atos de tortura, assassinato, violência sexual, perseguições políticas, dentre outros, praticados por regimes de exceção, costumam ficar mantidos em segredo durante e após o encerramento dos períodos autoritários. Desse modo, a busca pela verdade dos fatos que ocorreram nestes períodos constitui peça fundamental para concretizar todos os demais objetivos de qualquer justiça transicional, como a punição de agentes e indenização das vítimas ou seus familiares, além de possuir uma dimensão pedagógica, como será tratado no próximo item.

\subsection{CONSEQUÊNCIAS DA FALTA DE ACESSO À INFORMAÇÃO}

Parte da sociedade brasileira vem assistindo, com certa surpresa e assombro, ao crescimento de setores sociais que se declaram favoráveis ao retorno dos militares ao poder. É certo que em todo agrupamento social existem setores mais conservadores e setores mais progressistas, alguns

\footnotetext{
${ }^{2}$ VAN ZYL, Paul. Promovendo a justiça transicional em sociedades pós-conflito. Revista Anistia Política e Justiça de Transição / Ministério da Justiça. - N. 1 (jan. / jun. 2009). - Brasília : Ministério da Justiça , 2009. Disponível em: http://www.portalmemoriasreveladas.arquivonacional.gov.br/media/2009RevistaAnistia01.pdf. Acesso em: 28/10/2014. p. 32 .

${ }^{3}$ Ibidem. p. 34.
} 
mais outros menos favoráveis a medidas de intervenção estatal nas liberdades públicas para a observância da lei e da ordem. Porém, desde a redemocratização do país, ocorrida na década de 80 , estes setores mais conservadores não costumavam se manifestar publicamente, como recentemente ocorrido.

Em março de 2014, algumas centenas de pessoas participaram de uma manifestação em São Paulo denominada "Marcha da Família com Deus 2", relembrando acontecimento histórico ocorrido em 1964, quando meio milhão de pessoas participaram da "Marcha da Família com Deus, pela Liberdade", protestando contra o governo do então Presidente João Goulart. Na manifestação de 2014, juntamente com protestos contra atos de corrupção e contrários ao governo petista, alguns dos participantes defendiam uma intervenção militar no país.

Com o acirramento dos ânimos após as eleições presidenciais do final de 2014 e o inconformismo com a derrota de setores mais conservadores da sociedade, voltaram a acontecer várias manifestações em diversas capitais brasileiras nos meses de março, abril e junho de 2015. Nestes eventos, alguns reunindo milhares de pessoas, protestava-se contra a corrupção e o governo federal petista, pedindo-se o impeachment da Presidente Dilma Roussef, democraticamente eleita nos pleitos do ano anterior. Assim como na marcha de 2014, nos protestos de 2015 também foram bastante comuns os pedidos de intervenção militar no país.

Este apoio a um novo golpe militar vem crescendo nos últimos anos segundo dados de pesquisa. A Universidade Vanderbilt, dos Estados Unidos, em parceria com várias instituições da América Latina realiza uma pesquisa de opinião pública para medir o nível de apoio popular a intervenções militares nos países do continente. Os dados publicados em 2014, coletados pelo Instituto Vox Populi no Brasil, revelam que $48 \%$ da população brasileira acha que seria justificável um golpe militar para conter os escândalos de corrupção. Este percentual coloca nosso país na sexta posição entre os países da América Latina mais complacentes com um golpe militar. ${ }^{4}$

Além destas manifestações, talvez ainda mais grave, seja o apoio de grande parte da sociedade a medidas praticadas na época da ditadura

\footnotetext{
${ }^{4}$ SORANO, Vitor. Apoio a golpe militar cresce no Brasil desde 2012, mostra pesquisa. Último segundo - Ig, São Paulo, 28/03/2015. Disponível em: http://ultimosegundo.ig.com.br/brasil/2015-03-28/apoio-a-golpe-militar-cresce-no-brasil-desde-2012mostra-pesquisa.html. Acesso em:12/06/2015. p. 34.
} 
militar totalmente contrárias aos direitos humanos, como a prática da tortura.

Uma outra pesquisa publicada em 2012 pelo Núcleo de Estudos da Violência da USP revela que quase a metade dos brasileiros é favorável à tortura de acusados como forma de obtenção de informações sobre prática criminosa. Em levantamento realizado em 2010, 47,5\% dos entrevistados responderam ser favoráveis a que os tribunais brasileiros aceitem provas obtidas através de tortura. O levantamento ainda revela que quanto mais jovem o entrevistado, maior é a tendência em apoiar o uso das práticas de tortura. $^{5}$

\subsection{DIREITO À MEMÓRIA E À VERDADE}

Filósofos, sociólogos e historiadores tentam explicar este fenômeno do crescimento de ideias conservadoras e reacionárias, principalmente em setores mais jovens da sociedade. Uma das causas apontadas é o crescimento de acesso à internet e o surgimento das redes sociais, ambiente propício para divulgação de ideias, muitas vezes sem fundamento ou com fundamento equivocado, além daquelas carregadas de preconceito, ódio e desinformação.

Mas a principal causa apontada costuma ser a falta de acesso à informação do que verdadeiramente ocorreu durante o período de ditadura militar que controlou nosso país de 1964 a 1985.

Em março de 2015, em um seminário realizado no Instituto de Estudos Avançados da USP, a historiadora Heloísa Starling, professora da Faculdade de Filosofia e Ciências Humanas da UFMG e assessora da Comissão Nacional da Verdade, fez uma exposição sobre a importância do testemunho como dispositivo reconstituidor da ditadura militar. A historiadora defendeu a necessidade do conhecimento e divulgação dos fatos ocorridos durante o período ditatorial e alertou para os riscos dos mecanismos de esquecimento utilizados pela sociedade em um período pós-conflito.

\footnotetext{
${ }^{5}$ METADE dos brasileiros concorda com tortura de criminosos, diz pesquisa. Consultor jurídico, Brasil, 06/06/2012. Disponível em: http://www.conjur.com.br/2012-jun-06/metade-brasileiros-concorda-tortura-criminosos-pesquisa. Acesso em: 11/06/2015.
} 
Na avaliação de Starling, esses mecanismos de esquecimento ajudam a explicar os pedidos de intervenção militar no Brasil que figuraram na pauta de reinvindicações das manifestações de junho 2014 e que voltaram a aparecer nos protestos subsequentes. Para ela, os indivíduos que levantam essa bandeira constroem um imaginário do regime militar com base naquilo que lhes falta e, por isso, experimentam uma nostalgia do que nunca viveram.

As pessoas dizem que querem a ditadura, mas não têm a menor ideia do que querem dizer com isso. Extravasam com esse pedido um sentimento de impotência e desencanto. Trata-se de um olhar moralista: 'não tenho memória sobre o que aconteceu', observou, destacando a importância da verdade ser colocada na cena pública. ${ }^{6}$

No mesmo sentido, o historiador Enrique Serra Padrós, da Universidade Federal do Rio Grande do Sul reconhece que a luta pela Verdade e pela Justiça em sociedades que passam por momentos transicionais, possui quatro dimensões: histórica, pedagógica, ética e social. ${ }^{7}$

Sua dimensão pedagógica seria responsável para promover o encontro de gerações, sendo que:

O esclarecimento dos acontecimentos torna-se necessidade vital e funciona como ação a contrapelo diante de um dos objetivos estratégicos mais desejados pelos responsáveis e apoiadores das Ditaduras de Segurança Nacional: a desconexão entre as gerações que viveram sob o cotidiano dos regimes autoritários, e as que vieram depois. Tal desconexão se expressa, muitas vezes, no desconhecimento geral que essas novas gerações possuem sobre o passado

\footnotetext{
${ }^{6}$ DOURADO, Flávia. O testemunho como elo entre a memória e a história da ditadura militar. IEA - Instituto de Estudos Avançados da Universidade de São Paulo. São Paulo, 17/03/2015. Disponível em: <http://www.iea.usp.br/noticias/o-testemunho-comoelo-entre-a-memoria-e-a-historia-da-ditadura-militar>. Acesso em: 11/06/2015.

${ }^{7}$ PADRÓS, Enrique Serra. Ditadura brasileira: verdade, memória... e justiça? Historiae, (Rio Grande do Sul), (n. 3), (65-84), 2012. Disponível em: www.seer.furg.br/hist/article/viewFile/3262/1939. Acesso em: 10/06/2015. p. 68-71.
} 
recente, ou através de um precário e perturbador senso comum. Pode-se dizer que tal constatação é o resultado, mais do que a ausência de "políticas de memória", da aplicação deliberada de "políticas de esquecimento", ou seja, a proposição de ações de "esquecimento induzido": sonegação de informação; difusão de informações ambíguas; imprecisão conceitual; relativização da violência irradiada contra a população; apagamento das responsabilidades pelos crimes estatais; e a reafirmação de justificativas como a teoria dos dois demônios, ou da tese da ditabranda. ${ }^{8}$

O historiador conclui que esta reconstituição do elo geracional evita que os jovens do presente sejam reféns da ignorância a respeito dos escabrosos acontecimentos pretéritos e das lutas implementadas contra o regime de exceção, além de possibilitarem o desenvolvimento de mecanismos de prevenção de eventuais reversões autoritárias. ${ }^{9}$ Dentro deste contexto, ressalta que:

O desconhecimento e a desvalorização deste passado contribuiram para que as novas gerações tenham tido uma formação insuficiente, em termos políticos, tanto em relação a uma consciência cidadã e ética, quanto na exigência intransigente dos Direitos Humanos. Desconhecer a importância destes efeitos impede de perceber o significado da desconexão entre gerações. Há uma história dos pais e dos avós que foi cortada dos filhos e dos netos. O futuro pode reservar momentos de tensão e é claro que, caso isso ocorra, a ausência da apropriação dessa experiência social poderá ser fatal para aqueles que deverão enfrentar esses desafios. ${ }^{10}$

\footnotetext{
${ }^{8}$ PADRÓS, Enrique Serra. Ditadura brasileira: verdade, memória... e justiça? Historiae, (Rio Grande do Sul), (n. 3), (65-84), 2012. Disponível em: www.seer.furg.br/hist/article/viewFile/3262/1939. Acesso em: 10/06/2015. p. 69-70.

${ }^{9}$ Ibidem.

${ }^{10}$ Ibidem. p. 80.
} 
A necessidade de amplo conhecimento dos fatos passados, principalmente daqueles que ocorreram durante períodos autoritários, é unanimidade entre os representantes das ciências humanas e sociais para que as atuais gerações passem a conferir maior valor para as instituições democráticas e criem maior consciência sobre a importância do respeito aos direitos humanos.

Esta busca pela verdade costuma ser desenvolvida através de "políticas de memória", cujo conceito é abordado por Alexandra Barahona de Brito:

Pode-se definir a política de memória de duas maneiras. De forma restrita, consiste de políticas para a verdade e para a justiça (memória oficial ou pública); vista mais amplamente, é sobre como a sociedade interpreta e apropria o passado, em uma tentativa de moldar o seu futuro (memória social). Memória social é a criação de "comunidades imaginadas" e a construção de uma ordem moral. As "políticas de memória" sociais e culturais são parte integral do processo de construção de várias identidades coletivas sociais e políticas, que definem o modo como diferentes grupos sociais veem a política e os objetivos que desejam alcançar no futuro. A memória é uma luta sobre o poder e sobre quem decide o futuro, já que aquilo que as sociedades lembram e esquecem determina suas opções futuras. ${ }^{11}$

Detalhando melhor o conceito de políticas de memória e relacionando-o com atitudes práticas voltadas para familiares de desaparecidos políticos e demais vítimas de regimes ditatoriais, que ainda sentem os efeitos das graves violações de direitos humanos, Rogério Gesta Leal, entende que:

${ }^{11}$ BRITO, Alexandra Barahona de. Justiça transicional e a política da memória: uma visão global. Revista Anistia Política e Justiça de Transição / Ministério da Justiça. - N. 1 (jan. / jun. 2009). -- Brasília: Ministério da Justiça, 2009. Disponível em: http://www.portalmemoriasreveladas.arquivonacional.gov.br/media/2009RevistaAnistia01.pdf. Acesso em: 28/10/2014. p. 72. 
A Memória aqui opera como condição de possibilidade à superação destes problemas, compreendendo contextualmente o ocorrido, já que as feridas se dão em determinado marco historio. A par disto, estratégicas e políticas de memória usam de recursos locais e mecanismos de enfrentamento destas questões, associados a programas com estratégias de reconstrução identitária e democrática dos vínculos societais. Dentre as ações possíveis, pode-se destacar:

1) Reconstrução do âmbito social e cultural, com a utilização de atividades artesanais, artísticas, educativas, promoção de grupos de autoajuda, grupos de apoio etc;

2) Apoio individual e familiar centrado no trabalho em grupo, terapia individual e familiar, abrindo espaços para que as pessoas possam compartilhar suas experiências, o que pode ser útil para romper o silêncio;

3) Treinamento de pessoas locais em capacidades de apoio psicossocial para encarar e tratar o impacto traumático, com apoio e seguimento institucional;

4) Grupos de autoajuda, formados por sobreviventes de conflitos violentos e por familiares dos que morreram ou desapareceram, gerando espaços seguros e amistosos em que pode haver o compartilhamento de experiências.

5) Importância das formas simbólicas de expressão do reconhecimento do acorrido, como cerimônias e rituais, evidenciando ícones sociais que mantenham vivas as lições dolorosas do passado (memoriais, parques, placas nas ruas, celebração de aniversários etc.). ${ }^{12}$

Historiadores destacam, na construção destas políticas de memória, a simbologia presente nos espaços de memória, como no trecho abaixo de Enrique Padrós:

${ }^{12}$ LEAL, Rogério Gesta. Verdade, memória e justiça no Brasil: responsabilidades compartidas: morte, tortura, sequestro e desaparecimento de pessoas no regime militar brasileiro. Porto Alegre: Livraria do Advogado Editora, 2012. p. 59. 
Os "Espaços de Memória" abrangem dois grandes conjuntos de modalidades. O primeiro é associado, de forma geral, aos Espaços Físicos. Estes, quase sempre, estão marcados por terem sido lugares de luta e resistência, ou de aplicação das práticas repressivas do terror de Estado (centros de detenção, de tortura, etc.). (...) A segunda categoria de "Espaços de Memória" se relaciona com a idéia de estabelecer "Marcas" de eventos ou de pessoas. Monumentos, nomes de ruas, praças e prédios, museus e até memoriais, compõem este conjunto de registros. Neste caso, os lugares escolhidos podem ter relação direta com o que se quer registrar, ou podem ser alusões figuradas. ${ }^{13}$

Neste sentido, do até aqui exposto, depreende-se que, um dos principais objetivos de qualquer justiça de transição é a busca pela verdade dos fatos ocorridos durante um determinado período ditatorial, principalmente no tocante às graves violações aos direitos humanos. Esta busca, além de possibilitar a responsabilização dos agentes repressores, possui uma dimensão pedagógica de esclarecer as atuais gerações sobre a verdade dos fatos ocorridos e de promover uma valorização da cultura democrática e de respeito aos direitos humanos.

Esta busca pela verdade pode ser implementada através de políticas de memória que possuem, entre outras finalidades, a de confortar as vítimas e seus familiares, promovendo assim, um outro objetivo da justiça de transição que é a reconciliação da sociedade. Entre estas políticas, destaca-se a construção de espaços de memória, tais como monumentos e museus e a definição de marcas simbólicas, como placas e nomes de logradouros públicos.

\section{$2 \quad$ NOMES DE LOGRADOUROS PÚBLICOS}

\footnotetext{
${ }^{13}$ PADRÓS, Enrique Serra. Ditadura brasileira: verdade, memória... e justiça? Historiae, (Rio Grande do Sul), (n. 3), (65-84), 2012. Disponível em: www.seer.furg.br/hist/article/viewFile/3262/1939. Acesso em: 10/06/2015. p. 75.
} 


\subsection{SIMBOLOGIA PRESENTE NA DEFINIÇÃO DE NOMES DE LOGRADOUROS PÚBLICOS}

É incontestável o fato de que a definição de um nome para um logradouro público, tal como uma rua, avenida, praça, ponte, rodovia, escola, dentre outros, constitui-se em homenagem ou reconhecimento pelas contribuições prestadas à comunidade, no caso de pessoa, ou pode representar a necessidade de se promover determinados valores caros a esta comunidade (p. ex. "rua da justiça", "palácio da liberdade"), ou promover a lembrança de datas históricas importantes ("avenida sete de setembro", "rua treze de maio").

O historiador Reginaldo Benedito Dias, da Universidade Estadual de Maringá, ensina sobre a nominação de logradouros públicos:

Trata-se de recorrente mecanismo de construção da memória histórica, visto que se elege um personagem ou um fato para ser perenizado na lembrança coletiva. ${ }^{14}$

Dependendo da abrangência do nome que será estampado na placa, investe-se na composição da memória municipal ou nacional: "é na disputa pela definição de datas, símbolos e cerimônias comemorativas que começa a se delinear o caráter culturalmente arbitrário, histórico, social e politicamente construído da nação". ${ }^{15}$

(...) batizar um espaço público é uma das possibilidades de que o objeto da homenagem não venha a ser completamente esquecido fora dos círculos especializados. Uma vez formalizada, ela tem o potencial de incorporar fatos e personagens históricos em dados da vida cotidiana: "os elementos

\footnotetext{
${ }^{14}$ DIAS, Reginaldo Benedito. Sentido político da toponímia urbana: ruas com nomes de mortos e desaparecidos políticos da ditadura militar brasileira. Patrimônio e memória, (São Paulo), (v.8, n.1), jan-jun. 2012. Disponível em: <http://pem.assis.unesp.br/index.php/pem/article/view/98/98>. Acesso em: 11/06/2015.

15 CATELA apud DIAS, Reginaldo Benedito. Sentido político da toponímia urbana: ruas com nomes de mortos e desaparecidos políticos da ditadura militar brasileira. Patrimônio e memória, (São Paulo), (v.8, n.1), jan-jun. 2012. Disponível em: <http://pem.assis.unesp.br/index.php/pem/article/view/98/98>. Acesso em: 11/06/2015.
} 
da paisagem urbana e sua visualidade permitem que os transeuntes interpretem, no campo simbólico ou cognitivo, imagens, memórias e histórias da cidade ou do país". ${ }^{16}$

Reginaldo Dias ainda destaca que constitui prática comum a alteração de nomes dos logradouros públicos após períodos revolucionários ou de grande ruptura política, simbolizando as transformações ocorridas em determinada comunidade e a adoção de novos valores:

Rupturas históricas são pródigas na promoção de novos símbolos. A incidência do ato de batizar logradouros públicos é uma extensão da composição de um imaginário social coerente com o horizonte das mudanças. Em revoluções e grandes reviravoltas históricas, é comum constatar até a mudança de nomes de cidades.

Ao contrário do que concebe o senso comum, o passado se modifica. Não, evidentemente, o ocorrido, mas o que se sabe e como se interpreta o que aconteceu. Isso leva a disputa pela memória a se reproduzir em todos os meios, incluindo os nomes de ruas. Essa revisão de sentidos e de referências faz parte, não há dúvida, da luta social pelo presente e de sua relação com um passado vivo. A memória é, afinal, o suporte da identidade. ${ }^{17}$

\subsection{PROGRAMA NACIONAL DE DIREITOS HUMANOS E COMISSÃO NACIONAL DA VERDADE}

\footnotetext{
${ }^{16}$ PELEGRINI apud DIAS, Reginaldo Benedito. Sentido político da toponímia urbana: ruas com nomes de mortos e desaparecidos políticos da ditadura militar brasileira. Patrimônio e memória, (São Paulo), (v.8, n.1), jan-jun. 2012. Disponível em: <http://pem.assis.unesp.br/index.php/pem/article/view/98/98>. Acesso em: 11/06/2015. p. 161-162.

${ }^{17}$ DIAS, Reginaldo Benedito. Sentido político da toponímia urbana: ruas com nomes de mortos e desaparecidos políticos da ditadura militar brasileira. Patrimônio e memória, (São Paulo), (v.8, n.1), jan.-jun. 2012. Disponível em: http://pem.assis.unesp.br/index.php/pem/article/view/98/98. Acesso em: 11/06/2015. p. 162.
} 
Esta prática simbólica de mudança de nomes de logradouros públicos que homenageiam representantes da ditadura militar, já estava prevista para que ocorresse desde o $3^{\circ}$. Programa Nacional de Direitos Humanos do governo federal, de 2009, tendo constado também como recomendação da Comissão Nacional da Verdade, cujo relatório final foi publicado em 2014.

Em 2008, foi elaborado o $3^{\circ}$. Programa Nacional de Direitos Humanos (PNDH-3), fruto de várias reuniões em todos os estados brasileiros, entre representantes do governo e da sociedade civil, envolvidos na defesa dos direitos humanos. Foram ao todo 137 encontros com a participação de mais de 14 mil pessoas que culminaram com a $11^{\mathrm{a}}$. Conferência Nacional de Direitos Humanos e a divulgação do PNDH-3, que ingressou em nosso ordenamento jurídico através do Decreto No. 7.037 de 21 de dezembro de 2009. ${ }^{18}$

O PNDH-3 está estruturado em seis eixos orientadores, subdivididos em 25 diretrizes, 82 objetivos estratégicos que incorporam ou refletem os 7 eixos, as 36 diretrizes e as 700 resoluções da $11^{\mathrm{a}} \mathrm{CNDH}$. Entre estas diretrizes, consta a de número 25 :

Diretriz 25: Modernização da legislação relacionada com a promoção do direito à memória e à verdade, fortalecendo a democracia.

Objetivo Estratégico I: Suprimir do ordenamento jurídico brasileiro eventuais normas remanescentes de períodos de exceção que afrontem os compromissos internacionais e os preceitos constitucionais sobre Direitos Humanos.

Ações Programáticas:

a) Criar Grupo de Trabalho para acompanhar, discutir e articular, com o Congresso Nacional, iniciativas de legislação propondo: - revogação de leis remanescentes do período 1964-1985 que sejam contrárias à garantia dos Direitos Humanos ou tenham dado sustentação a graves violações; • revisão de propostas legislativas envolvendo retrocessos na

\footnotetext{
18 PROGRAMA Nacional de Direitos Humanos (PNDH-3) / Secretaria Especial dos Direitos Humanos da Presidência da República - - ver. e atual. - - Brasília: SEDH/PR, 2010. Disponível em: http://www.sdh.gov.br/assuntos/direito-para-todos/programas/pdfs/programa-nacional-de-direitos-humanos-pndh-3. Acesso em: 13/06/2015.
} 
garantia dos Direitos Humanos em geral e no direito à memória e à verdade.

b) Propor e articular o reconhecimento do status constitucional de instrumentos internacionais de Direitos Humanos novos ou já existentes ainda não ratificados.

c) Fomentar debates e divulgar informações no sentido de que logradouros, atos e próprios nacionais ou prédios públicos não recebam nomes de pessoas identificadas reconhecidamente como torturadores. (Redação dada pelo Decreto no 7.177, de 12.05.2010). ${ }^{19}$ (grifo nosso)

Um dos principais aspectos inerentes a uma Justiça de Transição, em 2011, a Lei 12.528 criou no Brasil a Comissão Nacional da Verdade, com a finalidade de examinar e esclarecer as graves violações de direitos humanos praticadas no período de 18 de setembro de 1946 até a data da promulgação da Constituição, a fim de efetivar o direito à memória e à verdade histórica e promover a reconciliação nacional. ${ }^{20}$

Ao longo de dois anos e sete meses de trabalho, 1121 depoimentos, mais de 80 audiências públicas em 20 estados brasileiros, os membros da CNV elaboraram um relatório final, composto de três volumes, com mais 3 mil páginas. Apurou graves violações aos direitos humanos praticados durante o período da ditadura militar por integrantes do regime, tais como a prática de tortura, violência sexual, execuções, ocultações de cadáveres e desaparecimentos forçados. ${ }^{21}$

O primeiro volume do relatório enumera as atividades realizadas pela CNV na busca pela verdade, descreve os fatos examinados e apresenta as conclusões e recomendações dos membros da CNV para que os fatos ali descritos não voltem a se repetir. Dentre estas recomendações, consta a de número 28, nos seguintes termos:

${ }^{19}$ PROGRAMA Nacional de Direitos Humanos (PNDH-3) / Secretaria Especial dos Direitos Humanos da Presidência da República - - ver. e atual. - - Brasília: SEDH/PR, 2010. Disponível em: http://www.sdh.gov.br/assuntos/direito-para-todos/programas/pdfs/programa-nacional-de-direitos-humanos-pndh-3. Acesso em: 13/06/2015.

${ }^{20}$ CONHEÇA e acesse o relatório final da CNV. Comissão Nacional da Verdade, Brasil, 10/12/2014. Disponível em: http://www.cnv.gov.br/index.php/outros-destaques/574-conheca-e-acesse-o-relatorio-final-da-cnv. Acesso em: 13/06/2015.

${ }^{21}$ Ibidem. 
[28] Preservação da memória das graves violações de direitos humanos

48. Devem ser adotadas medidas para preservação da memória das graves violações de direitos humanos ocorridas no período investigado pela $\mathrm{CNV}$ e, principalmente, da memória de todas as pessoas que foram vítimas dessas violações. Essas medidas devem ter por objetivo, entre outros:

a) preservar, restaurar e promover o tombamento ou a criação de marcas de memória em imóveis urbanos ou rurais onde ocorreram graves violações de direitos humanos;

b) instituir e instalar, em Brasília, um Museu da Memória.

49. Com a mesma finalidade de preservação da memória, a CNV propõe a revogação de medidas que, durante o período da ditadura militar, objetivaram homenagear autores das graves violações de direitos humanos. Entre outras, devem ser adotadas medidas visando:

a) cassar as honrarias que tenham sido concedidas a agentes públicos ou particulares associados a esse quadro de graves violações, como ocorreu com muitos dos agraciados com a Medalha do Pacificador; b) promover a alteração da denominação de logradouros, vias de transporte, edifícios e instituições públicas de qualquer natureza, sejam federais, estaduais ou municipais, que se refiram a agentes públicos ou a particulares que notoriamente tenham tido comprometimento com a prática de graves violações. ${ }^{22}$ (grifo nosso)

\subsection{ARGUMENTOS CONTRÁRIOS À ALTERAÇÃO DOS NOMES DE LOGRADOUROS}

Conforme já destacado, é de grande importância simbólica a alteração dos nomes de logradouros e prédios públicos que homenageiam

\footnotetext{
${ }^{22}$ CONHEÇA e acesse o relatório final da CNV. Comissão Nacional da Verdade, Brasil, 10/12/2014. Disponível em: http://www.cnv.gov.br/index.php/outros-destaques/574-conheca-e-acesse-o-relatorio-final-da-cnv. Acesso em: 13/06/2015.
} 
membros do período ditatorial, como marco da mudança de valores de nossa sociedade. Alteração esta recomendada no PNDH-3 e no relatório final da CNV. Entretanto, a necessidade desta prática está longe de atingir unanimidade na sociedade e na própria comunidade acadêmica.

Dentre os argumentos contrários predominam aqueles que acusam a mudança dos nomes de constituir política de mera vingança ou justiça de vencedores, além do fato de poder trazer ainda mais desinformação para as futuras gerações.

(...) cabe mencionar que a retirada de placas que mencionam nomes de funcionários vinculados à estrutura do Estado repressivo e antidemocrático, está longe do consenso imaginado, mesmo entre organizações sensíveis à luta pelos direitos humanos e recuperação da história e da memória. Efetivamente, trata-se de um tema polêmico: o que se faz com uma marca concreta da repressão? De forma geral, há duas grandes vertentes que defendem argumentos importantes, mas contrapostos. De um lado estão os que defendem a retirada sem contemplações; do outro, os que consideram que não se deve mexer em algo que já é patrimônio da cidade. Seja como for, ou se muda, ou então se deve iniciar uma ação educativa que esclareça e qualifique o protagonismo da mencionada figura (no caso, um articulador do Golpe de 64 e posterior ditador). É necessário ser responsável com essa questão, para evitar que a maior parte da população, que provavelmente não tem acesso a uma informação mais refinada, não seja vítima de um emaranhado de palavras imprecisas ou vazias de significado. ${ }^{23}$

Padrós ainda explica que a manutenção de nomes de ditadores em logradouros públicos, faria a comunidade refletir sobre quais os motivos que teriam levado parte da sociedade a homenageá-los. Concluindo

\footnotetext{
${ }^{23}$ PADRÓS, Enrique Serra. Ditadura brasileira: verdade, memória... e justiça? Historiae, (Rio Grande do Sul), (n. 3), (65-84), 2012. Disponível em: www.seer.furg.br/hist/article/viewFile/3262/1939. Acesso em: 10/06/2015. p. 77.
} 
que outro aspecto negativo da mudança, seria o de que os responsáveis pela homenagem a um ditador seriam esquecidos:

A retirada de um símbolo associado a um período repressivo pode ser solução simplista. A tentativa reparatória de impedir que persista esse tipo de reconhecimento público a cidadãos associados a práticas antidemocráticas, pode gerar um dano muito maior, o de impedir que se faça a devida reflexão, não sobre o "prócer" escolhido, mas sobre aqueles que, em dado momento históricos, decidiram homenageálo. Ou seja, dentro de essa perspectiva, poderia ser encarado como forma de desresponsabilização de um setor da sociedade, que pelos motivos que forem, agraciou alguém associado à ditadura. ${ }^{24}$

Somam-se a estes argumentos, outros de natureza mais prática e individual, como os inconvenientes e transtornos apontados pela população atingida pela alteração de endereço para o recebimento de correspondência e necessidade de modificação de escritura de imóvel no cartório de registro de imóveis.

\subsection{LOGRADOUROS PÚBLICOS E HOMENAGEM À DITADURA}

Reportagem do jornal "O Dia” revelou que existem no Brasil 205 logradouros públicos (ruas, avenidas e praças) como nomes que homenageiam membros integrantes dos governos da época da ditadura militar. $\mathrm{O}$ próprio jornal fez um levantamento junto ao Diretório Nacional de Endereço dos Correios, buscando 377 nomes apontados no relatório final da CNV como colaboradores, civis ou militares do regime de exceção, além

\footnotetext{
${ }^{24}$ PADRÓS, Enrique Serra. Ditadura brasileira: verdade, memória... e justiça? Historiae, (Rio Grande do Sul), (n. 3), (65-84), 2012. Disponível em: www.seer.furg.br/hist/article/viewFile/3262/1939. Acesso em: 10/06/2015. p. 78.
} 
dos cinco Presidentes militares. Ficaram de fora da pesquisa logradouros como pontes, viadutos, rodovias e escolas. ${ }^{25}$

São Paulo é o estado com o maior número de ocorrências, 58 (28\%), logo seguido pelo Rio de Janeiro, com 26 referências. Entre os nomes de ditadores mais homenageados, constam os do Marechal Castello Branco, com 54 ocorrências, seguido de Eduardo Gomes, com 48, Costa e Silva, 40 e Médice, com 9 ocorrências. ${ }^{26}$

O site UOL destacou que existem no Brasil 717 escolas, entre públicas e particulares com nomes dos generais da ditadura militar. Os maiores homenageados são Castello Branco, com 347 referências, Costa e Silva, com 209, Médice, 120, seguidos de Geisel e Figueiredo, com 23 e 18 referências respectivamente. 697 delas são públicas e 20 são particulares e a região do país com o maior número de ocorrências é o nordeste, com 385 unidades. $^{27}$

Segundo o jornal "O Estado de São Paulo", existem somente na cidade de São Paulo, 29 ruas com referência a integrantes do regime militar ou à ditadura. ${ }^{28} \mathrm{O}$ "Zero Hora" destacou que o estado do Rio Grande do Sul homenageia os presidentes do período de exceção em 78 ruas e escolas do estado. São 45 escolas no total e 33 logradouros entre ruas, avenidas, praças e bairros. Lá também os ditadores mais homenageados são, por ordem de ocorrências, Castello Branco, Costa e Silva e Médice. ${ }^{29}$

\footnotetext{
${ }^{25}$ VIEGAS, Nonato. Ditadura ainda é homenageada nas ruas: logradouros pelo país mantêm nomes acusados de crimes do regime de 64. O Dia, Rio de Janeiro, 27/12/2014. Disponível em: http://odia.ig.com.br/noticia/brasil/2014-12-27/ditadura-ainda-e-homenageada-nasruas.html. Acesso em: 12/06/2015.

${ }^{26}$ Ibidem.

${ }^{27}$ GENERAIS da ditadura dão nome a717 escolas do Brasil. UOL, São Paulo, 14/04/2014. Disponível em: http://educacao.uol.com.br/infograficos/2014/04/14/escolas-publicas-dominam-lista-com-nomes-de-ex-presidentes-do-regime-militar.htm. Acesso em: $14 / 06 / 2015$.

${ }^{28}$ HUPSEL FILHO, Valmar e ARRUDA, Roldão. São Paulo tem 29 ruas com referência a militares ou à ditadura. O Estado de S. Paulo, São Paulo, 28/01/2015, Política. Disponível em: http://politica.estadao.com.br/noticias/geral,sao-paulo-tem-29-ruas-com-referencia-amilitares-ou-a-ditadura,1626072. Acesso em: 14/06/2015.

${ }^{29}$ KANNENBERG, Vanessa. RS homenageia presidentes da ditadura militar em 78 ruas e escolas. Zero Hora, Porto Alegre, 15/01/2015. Disponível em: http://zh.clicrbs.com.br/rs/noticias/noticia/2015/01/rs-homenageia-presidentes-da-ditadura-militarem-78-ruas-e-escolas-4681449.html. Acesso em: 14/06/2015.
} 
De acordo com o Cadastro Nacional de Estádios da CBF, dos 739 estádios oficiais do país, apenas dois levam nomes de ex-presidentes militares. São eles o Estádio Presidente Emílio Garrastazu Médice, em Iabaiana (SE) e o Estádio Humberto de Alencar Castello Branco, conhecido como "Baetão", em São Bernardo do Campo (SP). ${ }^{30}$

Entretanto, existem mais alguns estádios que homenageiam em seus nomes, governadores biônicos, aqueles indicados pelos militares durante a ditadura. Entre eles, dois foram recentemente reformados e receberam jogos da Copa do Mundo do Brasil de 2014: o Estádio Governador Magalhães Pinto (o "Mineirão", em Belo Horizonte) e o Estádio Plácido Aderaldo Castelo (o "Castelão", em Fortaleza), referência ao governador do Ceará entre 1966 e $1971 .^{31}$

Os sites e jornais que veicularam estes dados alertam para o fato de que podem estar subdimensionados, não existindo números oficiais sobre a existência destes logradouros. Ainda assim, pode-se concluir que existe um número muito expressivo de logradouros e prédios públicos que homenageiam ditadores e responsáveis por atos de violação aos direitos humanos espalhados por todo o país, fato incompatível com os valores democráticos e civilizatórios que fundamentam nossa sociedade após o processo de redemocratização.

\subsection{INICIATIVAS PARA ALTERAÇÃO DOS NOMES DE LOGRADOUROS QUE HOMENAGEIAM A DITADURA}

Várias foram as iniciativas em diversos estados e cidades brasileiras para alteração dos nomes de logradouros públicos que homenageiam representantes da ditadura militar, apontados no item anterior deste trabalho.

Um dos casos mais conhecidos e emblemáticos ocorreu em 2014 em Salvador, onde o nome do antigo Colégio Estadual Presidente Emílio Garrastazu Médice foi alterado para Carlos Mariguella. Como se sabe, Mariguella foi um dos principais contestadores do regime militar, militante do

\footnotetext{
${ }^{30}$ OS ESTÁDIOS brasileiros que homenageiam a ditadura militar. Impedimento - Futebol e Cultura Sul-americana. Brasil, 01/04/2014. Disponível em: http://impedimento.org/osestadios-brasileiros-que-homenageiam-a-ditadura-militar/. Acesso em: 12/06/2015.

${ }^{31}$ Ibidem.
} 
Partido Comunista Brasileiro, chegou a ser considerado como inimigo número um do governo. Integrante da luta armada contra a ditadura, foi baleado, preso algumas vezes até ser morto em emboscada. Carlos Mariguella era baiano. ${ }^{32}$

A proposta de mudança do nome da escola foi amplamente debatida entre professores, alunos e pais de alunos que receberam informações sobre a biografia de Médice, Mariguella e outro candidato a ser homenageado com o nome da escola, o também baiano e geógrafo, Milton Santos. A escolha do nome ocorreu por eleição entre os alunos da escola. $O$ pedido foi encaminhado à Secretaria Estadual de Educação e atendido pelo Governo do estado. ${ }^{33}$

Alteração semelhante ocorreu mais recentemente no Maranhão. O Governador Flávio Dino, do PC do B, eleito em 2014, assinou um Decreto, logo em seu primeiro dia de mandato, proibindo a homenagem em logradouros públicos no estado de nomes publicados no relatório da Comissão Nacional da Verdade responsáveis por atos violadores dos direitos humanos. ${ }^{34}$

Simbolicamente em primeiro de abril de 2015, o governador alterou o nome de dez escolas públicas que homenageavam em seus nomes os ex-presidentes militares. Escolas que antes ostentavam os nomes de Castello Branco, Costa e Silva e Médice, passaram a homenagear figuras como o Paulo Freire, Vinícius de Moraes e outras pessoas de destaque estadual na área da educação. ${ }^{35}$

O caso é mais complicado quando se trata de logradouros públicos como ruas, travessas e avenidas. Nestas situações, além da necessidade de aprovação de projeto de lei pelos órgãos legislativos, ainda costumam existir objeções por parte dos moradores destas vias públicas em função

\footnotetext{
${ }^{32}$ MACHADO, Ingrid Maria. Governo muda oficialmente nome de colégio Médice para Mariguella. G1, Bahia, 17/02/2014. Disponível em: http://g1.globo.com/bahia/noticia/2014/02/governo-muda-oficialmente-nome-de-colegio-de-medici-para-marighella.html. Acesso em: 12/06/2015.

${ }^{33}$ Ibidem.

${ }^{34}$ GOVERNO do Maranhão muda nomes de escolas identificados com ditadura. Rede Brasil Atual, São Paulo, 31/03/2015. Disponível em: http://www.redebrasilatual.com.br/cidadania/2015/03/governo-do-maranhao-muda-nomes-de-escolas-identificados-com-ditadura-7977.html. Acesso em: 14/06/2015.

${ }^{35}$ Ibidem.
} 
dos transtornos causados por uma mudança de endereço para correspondências.

Pode ser apontado como exemplo desta dificuldade a situação da cidade de São Paulo, onde desde 2013 foi aprovada uma lei criando facilidades para a alteração de nomes de ruas que homenageiam membros da ditadura militar, bastando um abaixo-assinado com a adesão de 2/3 dos moradores da rua. Passado mais de um ano, nenhum abaixo-assinado tinha sido encaminhado para a prefeitura com esta intenção. ${ }^{36}$

Com base nesta mesma lei, o vereador Orlando Silva, do PC do B, apresentou projeto de lei para alterar o nome da Rua Doutor Sérgio Fleury, na vila Leopoldina, zona oeste da capital, para Rua Frei Tito. Fleury foi um dos delegados do DOPS (Departamento de Ordem Política e Social), considerado bastante linha dura, foi acusado de ser responsável por inúmeras práticas de tortura contra presos políticos, incluindo entre eles, o frade cearense Frei Tito. ${ }^{37}$

Representantes da Secretaria Municipal de Direitos Humanos fizeram várias visitas aos moradores da rua para explicar a importância simbólica e histórica da mudança de nome do local. Entretanto, não houve a sensibilização dos moradores: a maioria deles votou contra a proposta, alegando os inconvenientes com alteração de endereço para correspondência e em cartório de registro de imóveis. ${ }^{38}$

Mas o caso de maior repercussão nacional até o presente momento é o da ponte "Rio-Niterói", nomeada pela Lei 5.595/1970, editada pelo então Presidente General Emílio Garrastazu Médice, como Ponte Presidente Costa e Silva.

Segundo informações colhidas pelo Ministério Público Federal junto à empresa concessionária responsável pela sua manutenção, a ponte Rio-Niterói é uma das maiores do mundo, sendo a maior ponte do hemisfério sul do nosso planeta, detendo ainda o recorde de maior vão em viga reta contínua do mundo, em seu vão central de 300 metros de comprimento

\footnotetext{
${ }^{36}$ MORADORES resistem a trocar nomes da ditadura. Unicamp, Campinas, 25/02/2014. Disponível em: http://www.unicamp.br/unicamp/clipping/2014/02/25/moradores-resistemtrocar-nomes-da-ditadura. Acesso em: 14/06/2015.

${ }^{37}$ Ibidem.

${ }^{38}$ Ibidem.
} 
e 72 metros de altura. Portanto, evidente sua simbologia como obra de enorme importância artística, arquitetônica, estética e turística. ${ }^{39}$

Duas frentes se organizam para tentar a alteração do nome da ponte: uma através de projeto de lei no Congresso Nacional, outra através de ação judicial. Nenhuma das duas obteve êxito até o presente momento.

Tramita na Câmara dos Deputados um projeto de lei (PL 3388/2012) proposto pelo Deputado Chico Alencar do PSOL-RJ, para alterar o nome da ponte Rio-Niterói, para "Ponte Herbert de Souza - Betinho", sociólogo exilado durante o período da ditadura. Em novembro de 2014 o PL foi aprovado na Comissão de Cultura da Câmara, desde então encontra-se pendente de análise em outras comissões.

Ao mesmo tempo, o Ministério Público Federal do Rio de Janeiro ingressou com uma Ação Civil Pública para declarar a inconstitucionalidade da Lei 5.595/1970, que nomeou a ponte com o nome do ex-presidente Costa e Silva. Alegou, para tanto, que a manutenção do nome de um representante do regime que cometeu tantas atrocidades constitui-se em lesão ao direito à memória e ao patrimônio histórico-cultural do povo brasileiro, protegidos constitucionalmente.

A ação foi extinta sem julgamento de mérito pelo juiz de primeiro grau, por considerar o pedido juridicamente impossível:

De acordo com o eminente magistrado a quo, a postulação do MPF veicula uma "decisão política que deve ser tomada pela sociedade coletivamente, através de sua participação direta e de seus representantes no Legislativo, sob pena de ofensa ao art. 2o da Constituição Federal de 1988". Para o juízo de 1 grau, "é a sociedade que cabe julgar, em última análise e á que ela é construtora e beneficiária da

\footnotetext{
${ }^{39}$ RIO DE JANEIRO (BRASIL). Tribunal Regional Federal da 2a . Região. $10^{\mathrm{a}}$. Vara Federal Cível da Subseção Judiciária do RJ. Processo N. 0002039-10.2014.4.02.5101. Ação Civil Pública. Autor: Ministério Público Federal. Réu: União Federal e Concessionária CCR Ponte. Rio de Janeiro, 2015. Disponível em: www.prrj.mpf.mp.br/.../crimes.../atuacao1/...acao-ponte-rio-niteroi/. Acesso em: 10/06/2015.
} 
memória nacional - se o ex-Presidente Costa e Silva prestou, ou não, relevante serviço à Nação". ${ }^{40}$

A Procuradoria Regional da República do Rio de Janeiro está recorrendo da decisão.

Percebe-se, pois, que o caminho ainda é longo. Se for levado em consideração que o número de logradouros que homenageiam membros da ditadura militar atinge centenas de unidades em todo o país, somado aos posicionamentos contrários acima expostos, conclui-se que a luta pela alteração destes nomes de logradouros está apenas no começo.

Porém, o professor de relações internacionais da Universidade Federal do ABC, Gilberto Marangoni, adverte:

Manter tais denominações significa conservar viva a memória de gente que deve ser colocada em seu justo lugar na História: o daqueles que perpetraram crimes contra a democracia e a cidadania, prejudicaram o país e contribuíram para o atraso em vários campos de atividade.

Na Itália não existe rua, monumento ou edifício público com o nome de Benito Mussolini ou de outro funcionário graduado do regime fascista. A decisão faz parte de uma luta ideológica que visa extirpar as marcas da intolerância, da brutalidade e da xenofobia que marcaram a vida do país entre 1924 e 1944.

Tampouco há na Alemanha uma avenida Adolf Hitler, um aeroporto Herman Göering (que foi ás da aviação na I Guerra Mundial), um viaduto Joseph Goebbels ou coisas que o valham. Aliás, evitou-se durante décadas batizar crianças com o nome Adolf, por motivos mais ou menos óbvios.

Argentina, Chile e Uruguai também não fazem rapapés à memória de responsáveis pelos anos de terror institucionalizado. A cidade de Puerto Stroessner, no Paraguai, teve seu nome mudado para

\footnotetext{
${ }^{40}$ RIO DE JANEIRO (BRASIL). Tribunal Regional Federal da 2a ${ }^{\mathrm{a}}$ Região. $10^{\mathrm{a}}$. Vara Federal Cível da Subseção Judiciária do RJ. Processo N. 0002039-10.2014.4.02.5101. Ação Civil Pública. Autor: Ministério Público Federal. Réu: União Federal e Concessionária CCR Ponte. Rio de Janeiro, 2015. Disponível em: www.prrj.mpf.mp.br/.../crimes.../atuacao1/...acao-ponte-rio-niteroi/. Acesso em: 10/06/2015.
} 
Ciudad Del Este, assim que o ditador foi deposto, em 1989.

(...) Banir os nomes de gente dessa laia dos logradouros públicos é um bom passo para se consolidar a democracia. ${ }^{41}$

\section{CONSIDERAÇÕES FINAIS}

O Brasil foi um dos últimos países da América do Sul que, tendo passado por um longo período de ditadura militar, implementou esforços no sentido de concretizar uma justiça de transição. Um dos aspectos mais importantes de todo processo transicional é a busca pela verdade a respeito das graves violações de direitos humanos ocorridos durante o regime de exceção. Em nosso país, esta busca ocorreu bastante tardiamente. A Comissão Nacional da Verdade, criada com esta finalidade, só foi instalada quase trinta anos após o final do período ditatorial.

Esta política do esquecimento é uma das principais responsáveis pelo alto nível de desinformação, principalmente, da parcela mais jovem da sociedade brasileira a respeito das atrocidades cometidas durante a ditadura militar. Esta desinformação contribui para o aumento apurado em pesquisas e manifestado recentemente nas ruas de várias cidades brasileiras e nas redes sociais, de apoio a uma nova intervenção militar e até mesmo à prática da tortura no país.

Para corrigir estas distorções, existem as chamadas políticas de memória, que possuem uma dimensão pedagógica de reaproximar as atuais gerações dos valores democráticos e de respeito aos direitos humanos. Uma das formas de se concretizar os ideais destas políticas é através da construção de espaços de memória, tais como museus e memoriais, além da fixação de placas comemorativas e homenagens em nomes de logradouros públicos.

Revela-se bastante simbólica esta fixação de nomes em logradouros e prédios públicos, até mesmo como manifestação de poder. Muito uti-

\footnotetext{
${ }^{41}$ MARINGONI, Gilberto. Ditadores e torturadores não podem ser no-mes de ruas. Disponível em: http://cartamaior.com.br/?/Coluna/Ditadores-e-torturadores-nao-podemser-nomes-de-ruas/26541. Acesso em 09/06/2015.
} 
lizada pelos próprios militares que fixaram os nomes dos generais ex-presidentes em mais de 900 lugares entre logradouros e prédios públicos, como revelam algumas coletas de dados citados neste trabalho.

Apesar de não existir consenso na sociedade e na comunidade acadêmica sobre a prática da alteração destes nomes, esta medida foi estabelecida em diretriz no $3^{\circ}$. Programa de Direitos Humanos do governo federal, em 2009, além de constituir recomendação no relatório final da Comissão Nacional da Verdade, divulgado em 2014.

Neste sentido, algumas alterações de nomes de logradouros que homenageavam pessoas acusadas da prática de atos contrários aos direitos humanos durante o período da ditadura militar já foram realizadas. Outras estão em fase de estudo, encontrando alguma resistência por parte de membros dos poderes legislativos nos três níveis da federação, e de parcela da própria comunidade, mais preocupada com os transtornos práticos que esta espécie de alteração pode causar.

Recomenda-se, portanto, que estas alterações sejam precedidas de amplo debate e explicação para a comunidade da necessidade da alteração para reforçar os valores democráticos e de respeito aos direitos humanos por parte desta sociedade.

É flagrante a incompatibilidade com os compromissos assumidos perante a comunidade internacional e os princípios consagrados na Constituição, como o do respeito à dignidade da pessoa humana, o do objetivo de se construir uma sociedade livre, justa e solidária, além da prevalência dos direitos humanos, com a manutenção da homenagem em prédios e logradouros públicos a pessoas que participaram de regime baseado no desrespeito destes mesmos princípios.

\section{REFERÊNCIAS BIBLIOGRÁFICAS}

BRASIL. Tribunal Regional Federal da $2^{\mathrm{a}}$. Região. $10^{\mathrm{a}}$. Vara Federal Cível da Subseção Judiciária do RJ. Processo N. 000203910.2014.4.02.5101. Ação Civil Pública. Autor: Ministério Público Federal. Réu: União Federal e Concessionária CCR Ponte. Rio de Janeiro, 2015.2 Disponível em: www.prrj.mpf.mp.br/.../crimes.../atuacao-1/...acao-ponte-rioniteroi/.. Acesso em: 10/06/2015. 
BRITO, Alexandra Barahona de. Justiça transicional e a política da memória: uma visão global. Revista Anistia Política e Justiça de Transição / Ministério da Justiça. - N. 1 (jan. / jun. 2009). -Brasília: Ministério da Justiça , 2009. Disponível em: http://www.portalmemoriasreveladas.arquivonacional.gov.br/ media/2009RevistaAnistia01.pdf. Acesso em: 28/10/2014.

CONHEÇA e acesse o relatório final da CNV. Comissão Nacional da Verdade, Brasil, 10/12/2014. Disponível em: http://www.cnv.gov.br/index.php/outros-destaques/574conheca-e-acesse-o-relatorio-final-da-cnv. Acesso em: 13/06/2015.

DIAS, Reginaldo Benedito. Sentido político da toponímia urbana: ruas com nomes de mortos e desaparecidos políticos da ditadura militar brasileira. Patrimônio e memória, (São Paulo), (v.8, n.1), jan-jun. 2012.

Disponível

em: http://pem.assis.unesp.br/index.php/pem/article/view/98/98. Acesso em: 11/06/2015.

DOURADO, Flávia. O testemunho como elo entre a memória e a história da ditadura militar. IEA - Instituto de Estudos Avançados da Universidade de São Paulo. São Paulo, 17/03/2015. Disponível em: http://www.iea.usp.br/noticias/o-testemunho-como-eloentre-a-memoria-e-a-historia-da-ditadura-militar. Acesso em: $11 / 06 / 2015$.

GENERAIS da ditadura dão nome a717 escolas do Brasil. UOL, São Paulo, 14/04/2014. Disponível em: http://educacao.uol.com.br/infograficos/2014/04/14/escolaspublicas-dominam-lista-com-nomes-de-ex-presidentes-doregime-militar.htm. Acesso em: 14/06/2015.

GOVERNO do Maranhão muda nomes de escolas identificados com ditadura. Rede Brasil Atual, São Paulo, 31/03/2015. Disponível em: http://www.redebrasilatual.com.br/cidadania/2015/03/governo-domaranhao-muda-nomes-de-escolas-identificados-com-ditadura7977.html. Acesso em: 14/06/2015.

HUPSEL FILHO, Valmar e ARRUDA, Roldão. São Paulo tem 29 ruas com referência a militares ou à ditadura. O Estado de S. Paulo, São Paulo, 28/01/2015, Política. Disponível em: http://politica.estadao.com.br/noticias/geral,sao-paulo-tem- 
29-ruas-com-referencia-a-militares-ou-a-ditadura, 1626072.

Acesso em: 14/06/2015.

KANNENBERG, Vanessa. RS homenageia presidentes da ditadura militar em 78 ruas e escolas. Zero Hora, Porto Alegre, 15/01/2015. Disponível em: http://zh.clicrbs.com.br/rs/noticias/noticia/2015/01/rshomenageia-presidentes-da-ditadura-militar-em-78-ruas-eescolas-4681449.html. Acesso em: 14/06/2015.

LEAL, Rogério Gesta. Verdade, memória e justiça no Brasil: responsabilidades compartidas: morte, tortura, sequestro $\mathrm{e}$ desaparecimento de pessoas no regime militar brasileiro. Porto Alegre: Livraria do Advogado Editora, 2012.

MACHADO, Ingrid Maria. Governo muda oficialmente nome de colégio Médice para Mariguella. G1, Bahia, 17/02/2014. Disponível em: http://g1.globo.com/bahia/noticia/2014/02/governo-mudaoficialmente-nome-de-colegio-de-medici-paramarighella.html. Acesso em: 12/06/2015.

MARINGONI, Gilberto. Ditadores e torturadores não podem ser nomes de ruas. Disponível em: http://cartamaior.com.br/?/Coluna/Ditadores-e-torturadoresnao-podem-ser-nomes-de-ruas/26541. Acesso em 09/06/2015. METADE dos brasileiros concorda com tortura de criminosos, diz pesquisa. Consultor jurídico, Brasil, 06/06/2012. Disponível em: http://www.conjur.com.br/2012-jun-06/metade-brasileirosconcorda-tortura-criminosos-pesquisa. Acesso em: 11/06/2015. MORADORES resistem a trocar nomes da ditadura. Unicamp, Campinas, 25/02/2014. Disponível em: http://www.unicamp.br/unicamp/clipping/2014/02/25/morado res-resistem-trocar-nomes-da-ditadura. Acesso em: 14/06/2015. OS ESTÁDIOS brasileiros que homenageiam a ditadura militar. Impedimento - Futebol e Cultura Sul-americana. Brasil, 01/04/2014. Disponível em: http://impedimento.org/os-estadiosbrasileiros-que-homenageiam-a-ditadura-militar/. Acesso em: $12 / 06 / 2015$.

PADRÓS, Enrique Serra. Ditadura brasileira: verdade, memória... e justiça? Historiae, (Rio Grande do Sul), (n. 3), (65-84), 2012. Disponível

em: 
www.seer.furg.br/hist/article/viewFile/3262/1939. Acesso em: 10/06/2015.

PROGRAMA Nacional de Direitos Humanos (PNDH-3) / Secretaria Especial dos Direitos Humanos da Presidência da República - ver. e atual. - - Brasília: SEDH/PR, 2010. Disponível em: http://www.sdh.gov.br/assuntos/direito-paratodos/programas/pdfs/programa-nacional-de-direitoshumanos-pndh-3. Acesso em: 13/06/2015.

SORANO, Vitor. Apoio a golpe militar cresce no Brasil desde 2012, mostra pesquisa. Último segundo - Ig, São Paulo, 28/03/2015. Disponível em: http://ultimosegundo.ig.com.br/brasil/2015-0328/apoio-a-golpe-militar-cresce-no-brasil-desde-2012mostra-pesquisa.html. Acesso em:12/06/2015.

VAN ZYL, Paul. Promovendo a justiça transicional em sociedades pósconflito. Revista Anistia Política e Justiça de Transição / Ministério da Justiça. - N. 1 (jan. / jun. 2009). - Brasília: Ministério da Justiça, 2009. Disponível em: http://www.portalmemoriasreveladas.arquivonacional.gov.br/ media/2009RevistaAnistia01.pdf. Acesso em: 28/10/2014.

VIEGAS, Nonato. Ditadura ainda é homenageada nas ruas: logradouros pelo país mantêm nomes acusados de crimes do regime de 64. O Dia, Rio de Janeiro, 27/12/2014. Disponível em: http://odia.ig.com.br/noticia/brasil/2014-12-27/ditaduraainda-e-homenageada-nas-ruas.html. Acesso em: 12/06/2015. 